\title{
Expansion of guidance for the day 8 initiation dose of paliperidone palmitate to avoid a missed dose
}

\author{
Mahesh N Samtani' \\ Isaac Nuamah' \\ Srihari Gopal' \\ Bart Remmerie ${ }^{2}$ \\ Jennifer Kern Sliwa ${ }^{3}$ \\ Larry Alphs ${ }^{3}$
}

'Janssen Research and Development, LLC, NJ, USA; ${ }^{2}$ Janssen Research and Development, LLC, Division of Janssen Pharmaceutica NV, Beerse, Belgium; 3 Janssen Scientific Affairs, LLC, NJ, USA

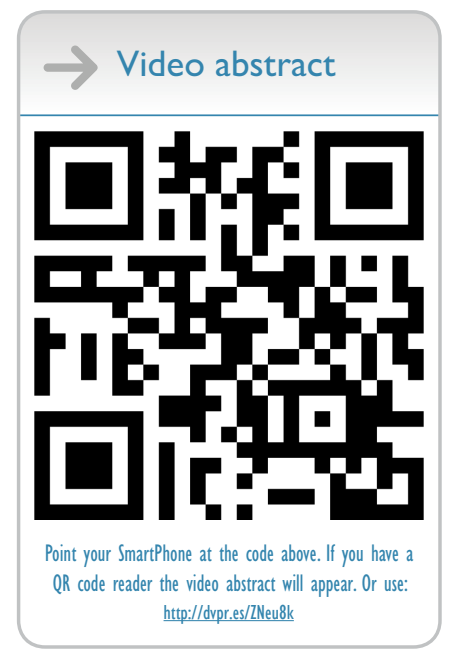

Correspondence: Mahesh N Samtani Clinical Pharmacology, Advanced PK-PD Modeling and Simulation, Janssen Research and Development, LLC 920 Route 202, PRD 2723, Raritan, NJ 08869, USA

$\mathrm{Tel}+$ I 9087045367

Fax + I 9089272573

Email msamtani@its.jnj.com
This article was published in the following Dove Press journal:

Neuropsychiatric Disease and Treatment

18 May 2013

Number of times this article has been viewed

Background: Paliperidone palmitate (PP) is a long-acting injectable formulation of an atypical antipsychotic, paliperidone. Its dose can be expressed in milligram or milligram equivalents (mg eq) of active paliperidone (39, 78, 117, 156, and $234 \mathrm{mg}$ of PP correspond to 25, 50, 75, 100 , and $150 \mathrm{mg}$ eq of paliperidone). The recommended initiation dosing regimen for PP is 150 [day 1]/100[day 8] mg eq. Labeling guidance allowed a \pm 2 day window for the day 8 injection that provides more flexibility with patient scheduling and avoids missing the day 8 initiation dose. Recently, expansion of the day 8 dosing window from \pm 2 to \pm 4 days has been approved in the United States based on results obtained from the model-based simulations and review of safety data presented here.

Methods: The predicted exposure for the recommended initiation regimen of PP was compared with day $1 /$ day 4 , and day 1 /day 12 dosing scenarios; each scenario was compared with the highest clinically evaluated initiation regimen (150[day 1]/150[day 8] $\mathrm{mg}$ eq) and to the recommended $6 \mathrm{mg}$ /day oral dose of extended-release paliperidone.

Results: Simulated exposures with PP $150 \mathrm{mg}$ eq on day 1 and $100 \mathrm{mg}$ eq on days 4, 8, or 12 overlap considerably, with $\pm 3 \mathrm{ng} / \mathrm{mL}$ variation in median maximum plasma concentrations. Based upon pharmacokinetic bridging/bracketing, the peak concentration with PP 150/100 mg eq [days 1/4] was lower than that with the highest initiation regimen. Exposures for PP $150 \mathrm{mg}$ eq on day 1 and $100 \mathrm{mg}$ eq on days 4,8 , or 12 were maintained close to those of $6 \mathrm{mg}$ of paliperidone extended-release.

Conclusion: These simulations indicate that using the expanded dosing window of \pm 4 days has little effect on paliperidone exposure. A review of the overall pattern of treatment-emergent adverse events did not identify any new safety risks associated with the expanded dosing window.

Keywords: dosing window expansion, initiation regimen, long-acting-injectable, pharmacokinetic bridging, paliperidone palmitate, population pharmacokinetics

\section{Introduction}

Poor compliance with long-term treatment is a common problem associated with all chronic medical conditions and can be particularly problematic among patients with schizophrenia. This poses major challenges in ensuring continuous antipsychotic therapy. In these patients, continuous antipsychotic therapy is essential for achieving sustained symptom control and reducing the risk of relapse and rehospitalization. Long-acting injectable antipsychotics provide a sustained release profile, resulting in therapeutic concentrations over several weeks and eliminating the need for daily dosing. Thus, long-acting injectable antipsychotic medications, which are administered 
by a health care professional on a regular schedule, provide uninterrupted drug delivery with a convenient dosing interval, and also offer information about the patient's condition during known treatment adherence. Taken together, these characteristics provide greater potential for continuous effective exposure in patients treated with long-acting injectables.

Paliperidone palmitate (PP) is a once-monthly, longacting injectable formulation of paliperidone approved in several countries for the treatment of schizophrenia in adults. The dose of PP can be expressed in $\mathrm{mg}$ or as $\mathrm{mg}$ equivalents (mg eq) of active paliperidone. Specifically, 39, 78, 117, 156, and $234 \mathrm{mg}$ of PP correspond to 25, 50, 75, 100, and $150 \mathrm{mg}$ eq of paliperidone.

Following intramuscular administration of two initiation doses given one week apart in the deltoid muscle, PP is administered monthly at doses ranging from 25 to $150 \mathrm{mg}$ eq, in either the deltoid or gluteal muscle. ${ }^{1}$ The recommended initiation regimen for PP is $150 \mathrm{mg}$ eq on day 1 followed by $100 \mathrm{mg}$ eq on day 8 , using a 1.0 inch needle in patients $<90 \mathrm{~kg}$ and a 1.5 inch needle in patients $\geq 90 \mathrm{~kg} .{ }^{2}$ Based upon data from model-based pharmacokinetic simulations and clinical trials, the label provides guidance to health care providers when patients miss the day 8 initiation dose, indicating that it may be administered within \pm 2 days, without a clinically significant impact on the plasma concentrations of paliperidone. ${ }^{3}$ Recently, an expansion of the dosing window from \pm 2 to \pm 4 days for a missed day 8 injection has been approved by the United States Food and Drug Administration (FDA); the PP label has been updated accordingly. ${ }^{1,4} \mathrm{We}$ report results of the analysis, that formed the basis for the PP label update. The analysis included model-based simulations to evaluate the potential effects of the day 8 dosing window expansion on paliperidone plasma exposures and potential implications on the safety and efficacy profile.

\section{Materials and methods \\ Pharmacokinetic data from clinical trials for model verification}

Pharmacokinetic data from two multiple-dose studies of PP in patients with schizophrenia were used to support the model-based simulation exercise. The first study was a long-term (53-week), open-label, study (ClinicalTrials. gov identification, NCT01150448) in which PP was administered with an initiation regimen of $150 \mathrm{mg}$ eq on both days 1 and 8 in the deltoid muscle, and then once monthly in the deltoid or gluteal muscle. ${ }^{5}$ The second study was a randomized, double-blind, double-dummy, active-controlled, 13-week study (ClinicalTrials.gov identification number, NCT00589914) in which the initiation regimen was $150 \mathrm{mg}$ eq on day 1 (deltoid), and then $100 \mathrm{mg}$ eq on day 8 (deltoid). ${ }^{6}$ In both studies, blood samples for the pharmacokinetic analysis were collected at baseline and at regular intervals thereafter. Detailed study designs and methodologies for these studies have been described previously. ${ }^{5,6}$

Steady-state pharmacokinetic data for paliperidone extended-release were available for: 31 patients with schizophrenia from a randomized, double-blind, placebocontrolled study (ClinicalTrials.gov identification number, NCT00074477), in which paliperidone extended-release was administered for one week $;^{7}$ and 140 patients with schizophrenia who underwent an oral tolerability test with 6 days of paliperidone extended-release treatment before receiving PP in a randomized, double-blind, placebo-controlled, 13-week study (ClinicalTrials.gov identification number, NCT00590577).

Plasma concentrations of paliperidone for all pharmacokinetic samples were determined using validated liquid chromatography coupled with a tandem mass spectrometry method, with a limit of quantification of $0.1 \mathrm{ng} / \mathrm{mL} .^{5-9}$

\section{Dataset preparation and analysis software} Dataset preparation was performed using $\mathrm{SAS}^{\circledR}$ version 9.1.3 (SAS Institute Inc, Cary, NC, USA) and S-Plus ${ }^{\circledR}$ 6.2 software (Insightful Corporation, Seattle, WA, USA). The database was prepared according to the format required by the NONMEM software. Analyses were performed using the nonlinear mixed-effect approach as implemented in NON$\mathrm{MEM}^{\circledR} \mathrm{V}$ and VI (NONMEM users guides, Icon Development Solutions, Ellicott City, MD, USA) and visualization of results was performed using S-Plus ${ }^{\circledR}$ version 6.2.

\section{Pharmacokinetic simulations}

The simulations are based on two historical population pharmacokinetic models for $\mathrm{PP}^{10}$ and paliperidone extended-release, ${ }^{11}$ which have been described in detail and used for simulations in a previously published report. ${ }^{3}$ Briefly, a one-compartment model with first-order elimination was used to simulate the pharmacokinetics of paliperidone after intramuscular administration of PP. The absorption submodel allowed a fraction of the dose to enter the central compartment fairly quickly via a zeroorder process. After a lag time, the remaining fraction of the dose entered the systemic circulation via a first-order 
process that determined the shape of the pharmacokinetic profile following intramuscular injection. In addition, the pharmacokinetics of paliperidone extended-release was simulated using a two-compartment disposition model with linear elimination from the central compartment. Oral absorption was described using a sequential zero order input into a depot compartment and first-order absorption with a lag time from the depot to the central compartment. To assess further the predictive performance of the historical population models, a visual predictive check $^{12}$ was performed for plasma profiles from the above-mentioned studies. Data from only the first 5 weeks from two studies ${ }^{5,6}$ were utilized for the PP visual predictive check because the objective of the analysis was to assess the model's ability to predict the pharmacokinetic profile after different PP initiation regimens.

Datasets were simulated based on the fixed effect (typical parameter estimates and covariate effects) and random effect (intrapatient variability, interoccasion variability, and residual variability) estimates in the historical PP populationpharmacokinetic model. ${ }^{10}$ Simulated datasets had study design features and covariates (ie, dosing information and demographics) similar to the above-mentioned studies. A visual predictive check was performed after the 5th, 50th, and 95th percentiles were calculated from the simulated profiles. ${ }^{12}$ These percentiles were superimposed on the raw observed data to allow assessment of model predictability. All plasma samples with quantifiable concentrations of paliperidone, with date and time of sampling, including the dosing history, were used in the plots for the visual predictive check. Using the same methodology, a visual predictive check was also performed to assess the ability of the population pharmacokinetic model for paliperidone extended-release ${ }^{11}$ to predict steady-state levels of paliperidone at the recommended $6 \mathrm{mg}$ dose. The observed paliperidone data and demographic characteristics for the paliperidone extendedrelease visual predictive check were derived from the studies by Kramer et $\mathrm{al}^{7}$ and Pandina et al. ${ }^{8}$

Once the historical population pharmacokinetic models were verified (ie, the visual predictive checks were found to be satisfactory), these models were used for the simulation exercise. Paliperidone plasma concentrations were simulated based on final estimates of the population pharmacokinetic models for $\mathrm{PP}^{10}$ and paliperidone extended-release. ${ }^{11}$ For each dataset, the covariates of interest were obtained by resampling from the patient covariates (ie, the patient is the resampling unit) available in the population pharmacokinetic database ${ }^{10}$ and the joint distribution of patient-specific characteristics was maintained. A 5000-patient Monte Carlo simulation of pharmacokinetic profiles was conducted for various scenarios, as described in Table 1. Medians and $90 \%$ prediction intervals were computed from the simulated profiles to allow visualization of results. The first set of simulations compared the recommended initiation dosage of $150 \mathrm{mg}$ eq on day 1 followed by $100 \mathrm{mg}$ eq on day 8 , with PP initiation doses (150 mg eq and $100 \mathrm{mg}$ eq) administered on day $1 /$ day 4 and on day 1 /day 12 . The second set of simulations compared the administration of the second initiation dose $(100 \mathrm{mg}$ eq) on day 4, day 8 , or day 12 with initiation regimen of $150 \mathrm{mg}$ eq on both days 1 and 8 . The third set of simulations compared the recommended daily dose $(6 \mathrm{mg})$ of the oral formulation paliperidone extended-release with the $150 / 100 \mathrm{mg}$ eq initiation doses administered on days 1 and 4, days 1 and 8 , and days 1 and 12 .

Finally, safety data during the first 5 weeks of two previous clinical studies (ClinicalTrials.gov identification numbers, NCT00590577 and NCT01150448) of $\mathrm{PP}^{5,8}$ were compared in order to assess the potential safety profile with an initiation regimen of $150 \mathrm{mg}$ eq on day 1 and $100 \mathrm{mg}$ eq on day 4.

\section{Results}

\section{Visual predictive check}

Pharmacokinetic profiles obtained during the first 5 weeks from 407 participants who received the initiation regimen of $150 \mathrm{mg}$ eq on day 1 and $100 \mathrm{mg}$ eq on day $8,{ }^{6}$ were compared with the simulated profiles in order to verify the PP population

Table I Summary of paliperidone palmitate initiation regimen simulations

\begin{tabular}{|c|c|}
\hline Set of simulations & $\begin{array}{l}\text { Each subset was } \\
\text { compared with }\end{array}$ \\
\hline \multicolumn{2}{|l|}{ First set } \\
\hline $\begin{array}{l}\text { PP I } 50 \mathrm{mg} \text { eq/ } / 00 \mathrm{mg} \text { eq day } \mathrm{I} / \text { day } 4 \\
\text { PP I50 mg eq//00 mg eq day I/day I } 2\end{array}$ & $\begin{array}{l}\mathrm{PP} / 50 \mathrm{mg} \text { eq/ } 100 \mathrm{mg} \text { eq } \\
\text { day I/day } 8 \text { (recommended } \\
\text { initiation dosage) }\end{array}$ \\
\hline \multicolumn{2}{|l|}{ Second set } \\
\hline $\begin{array}{l}\text { PP I50 mg eq//00 mg eq day I/day } 4 \\
\text { PP I50 mg eq// } 100 \mathrm{mg} \text { eq day I/day } 8 \\
\text { PP I50 mg eq// } 100 \mathrm{mg} \text { eq day } \mathrm{I} / \text { day } \mathrm{I} 2\end{array}$ & $\begin{array}{l}\text { PP I } 50 \mathrm{mg} \text { eq/ I } 50 \mathrm{mg} \text { eq } \\
\text { day I/day } 8 \text { (highest clinically } \\
\text { tested dosage) }\end{array}$ \\
\hline \multicolumn{2}{|l|}{ Third set } \\
\hline $\begin{array}{l}\text { PP I } 50 \mathrm{mg} \text { eq/ } / 00 \mathrm{mg} \text { eq day } \mathrm{I} / \text { day } 4 \\
\text { PP } 150 \mathrm{mg} \text { eq//00 mg eq day I/day } 8 \\
\text { PP I50 mg eq// } 100 \mathrm{mg} \text { eq day } \mathrm{I} / \text { day } \mathrm{I} 2\end{array}$ & $\begin{array}{l}\text { Paliperidone ER (oral) } 6 \mathrm{mg} \\
\text { once-daily (recommended oral } \\
\text { dosage) }\end{array}$ \\
\hline
\end{tabular}

Abbreviations: ER, extended-release; PP, paliperidone palmitate; $\mathrm{mg}$ eq, milligram equivalents. 
pharmacokinetic model. Similarly, the pharmacokinetic data from 199 participants who received the initiation regimen of $150 \mathrm{mg}$ eq on days 1 and $8^{5}$ were also compared with the simulated profiles. The results of these comparisons showed that the simulated profiles obtained using the PP population pharmacokinetic model were similar to the pharmacokinetic profiles obtained in two PP clinical studies (Figures 1 and 2). It should be noted that the observed concentrations are slightly higher than the simulated values in Figure 2; however the difference is likely to be clinically irrelevant. Moreover, the simulated curves for $150 \mathrm{mg}$ eq/150 mg eq initiation (see next section) will represent conservative predictions since the actual concentrations will be higher than the modelbased predictions at the higher doses. In addition, the PK profiles for $150 \mathrm{mg}$ eq/100 mg eq and $150 \mathrm{mg}$ eq/150 mg eq day 1/day 8 from study NCT00590577 have been recently published and these profiles were compared with the model based predictions. ${ }^{3}$ For study NCT00590577 the model accurately predicted the exposure for both the lower and higher initiation regimens. Thus, the small discrepancy in predictions for NCT01150448 could in part be due to a studyrelated effect. Finally, the paliperidone extended-release data from previous studies ${ }^{7,8}$ show considerable similarity with the population pharmacokinetic simulation for paliperidone extended-release at steady-state for the $6 \mathrm{mg}$ dose (Figure 3). These comparisons add confidence to the population pharmacokinetic models and support their use as simulation tools for assessing the day $8 \pm 4$ day dose window for PP.

\section{Simulation exercises}

When comparing the effects of different days for the second initiation dosing, the comparisons were quantitatively characterized (Table 2) in addition to their visualization. Simulated plasma concentration profiles of PP with a second initiation dose administered on day $8 \pm 4$ days versus the recommended day $1 /$ day 8 regimen showed considerable overlap, with a $\pm 3 \mathrm{ng} / \mathrm{mL}$ variation in median maximum plasma concentrations (Figure 4). These minor differences suggest that PP $150 \mathrm{mg}$ eq administered on day 1 followed by $100 \mathrm{mg}$ eq administered \pm 4 days around the recommended

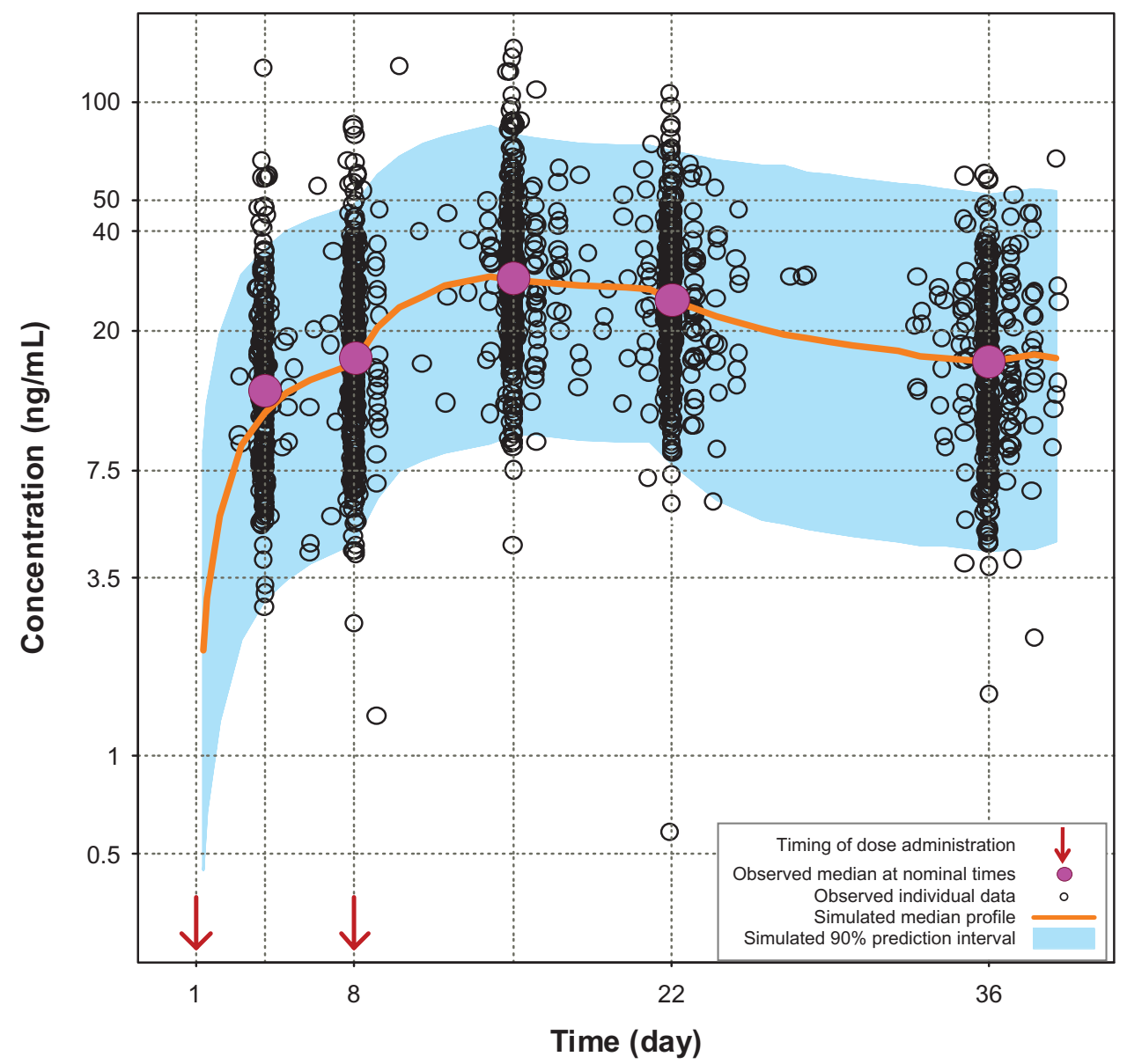

Figure I Comparison of model-based projections versus observed data for the initial 5 weeks of treatment with PP I50 mg eq on day I followed by I00 mg eq on day 8 . Abbreviations: $\mathrm{mg}$ eq, milligram equivalents; PP, paliperidone palmitate. 


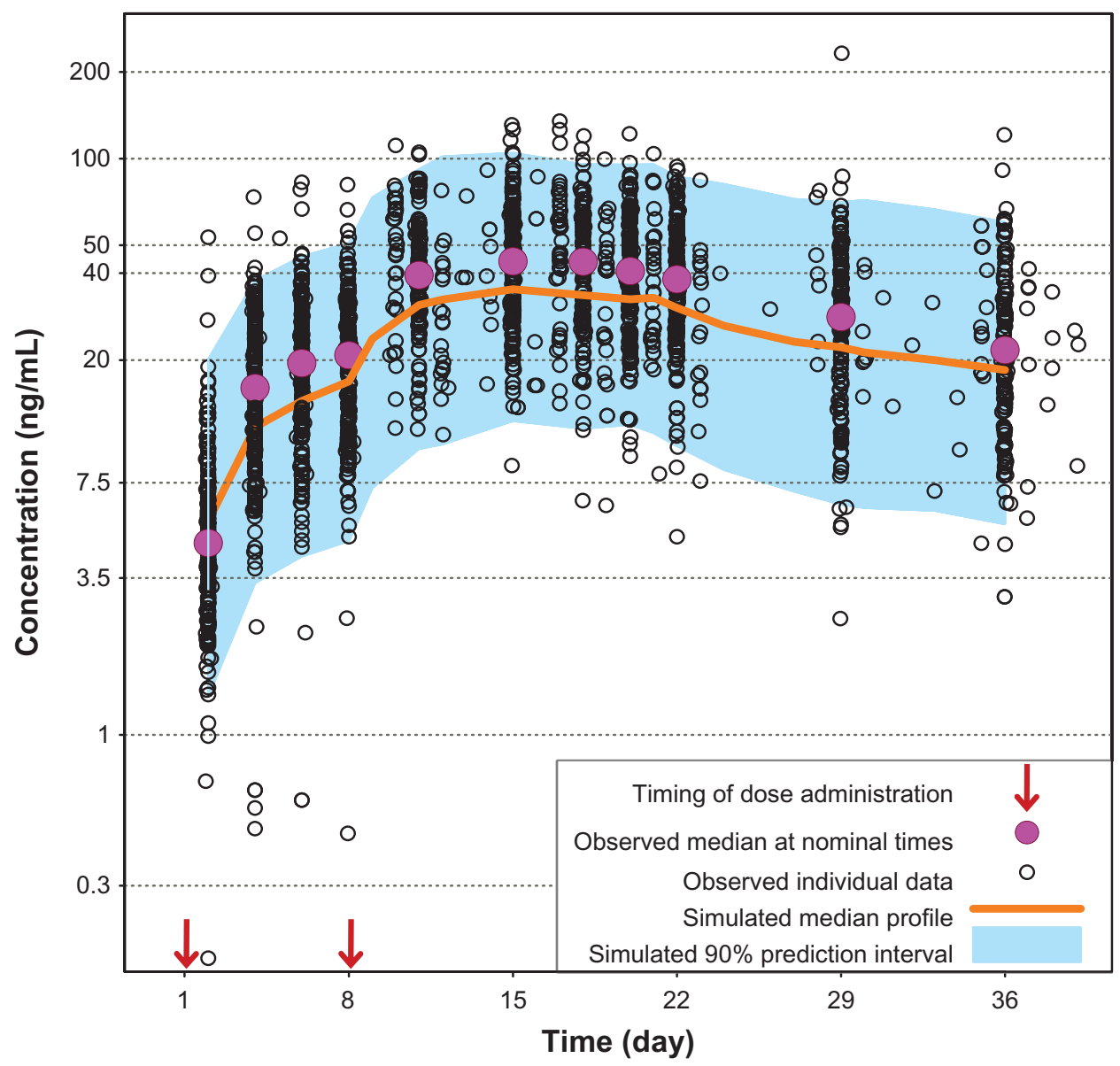

Figure 2 Comparison of model-based projections versus observed data for the initial 5 weeks of treatment with PP I50 mg eq on both days I and 8 . Abbreviations: $\mathrm{mg}$ eq, milligram equivalents; PP, paliperidone palmitate.

day 8 dose has minimal effects on the pharmacokinetic profile. Furthermore, the concentrations for the day $1 /$ day 4 regimen exhibited a minor excursion that exceeded the exposure window for the recommended day $1 /$ day 8 regimen by approximately one day around the peak plasma concentration $\left(\mathrm{C}_{\max }\right)$, which is probably clinically irrelevant.

Administration of the second initiation dose of PP (100 mg eq) at day 4, day 8, or day 12 produced plasma exposures that did not exceed the maximum exposure observed with the initiation regimen of $150 \mathrm{mg}$ eq on day 1 and $150 \mathrm{mg}$ eq on day 8 (Figure 5). The peak concentration from the PP $150 \mathrm{mg}$ eq on day 1 and $100 \mathrm{mg}$ eq on day 4 administration was below the paliperidone exposure observed with the initiation regimen of $150 \mathrm{mg}$ eq on days 1 and 8 (Figure 5). Based upon the pharmacokinetic bridging or a bracketing approach, exposure of paliperidone with $150 \mathrm{mg}$ eq on day 1 and $100 \mathrm{mg}$ eq on day 4 falls within the exposure range for the recommended initiation regimen of $150 \mathrm{mg}$ eq on day 1 and $100 \mathrm{mg}$ eq on day 8 and the highest initiation regimen of $150 \mathrm{mg}$ eq on both days 1 and 8 . This indicates that the proposed flexible dosing around the recommended day 8 injection would not pose a safety concern during the initiation phase.

Finally, comparison of paliperidone exposures from multiple daily doses of $6 \mathrm{mg}$ of paliperidone extendedrelease (recommended oral dose) with PP $150 \mathrm{mg}$ eq administered on day 1 followed by $100 \mathrm{mg}$ eq on day 4 , day 8 , and day 12 showed that the plasma concentrations of paliperidone were only slightly higher than the desired paliperidone extended-release $6 \mathrm{mg}$ exposure during the month after the second initiation dose (Figure 6). This indicates that the proposed flexible dosing around the recommended day 8 injection would not pose an efficacy concern during the initiation phase.

\section{Safety}

Review of safety data from the clinical studies that evaluated the highest initiation regimen of PP (150 mg eq on day 1 and $150 \mathrm{mg}$ eq on day 8) indicated that the highest initiation regimen was well tolerated with a safety profile similar to that 


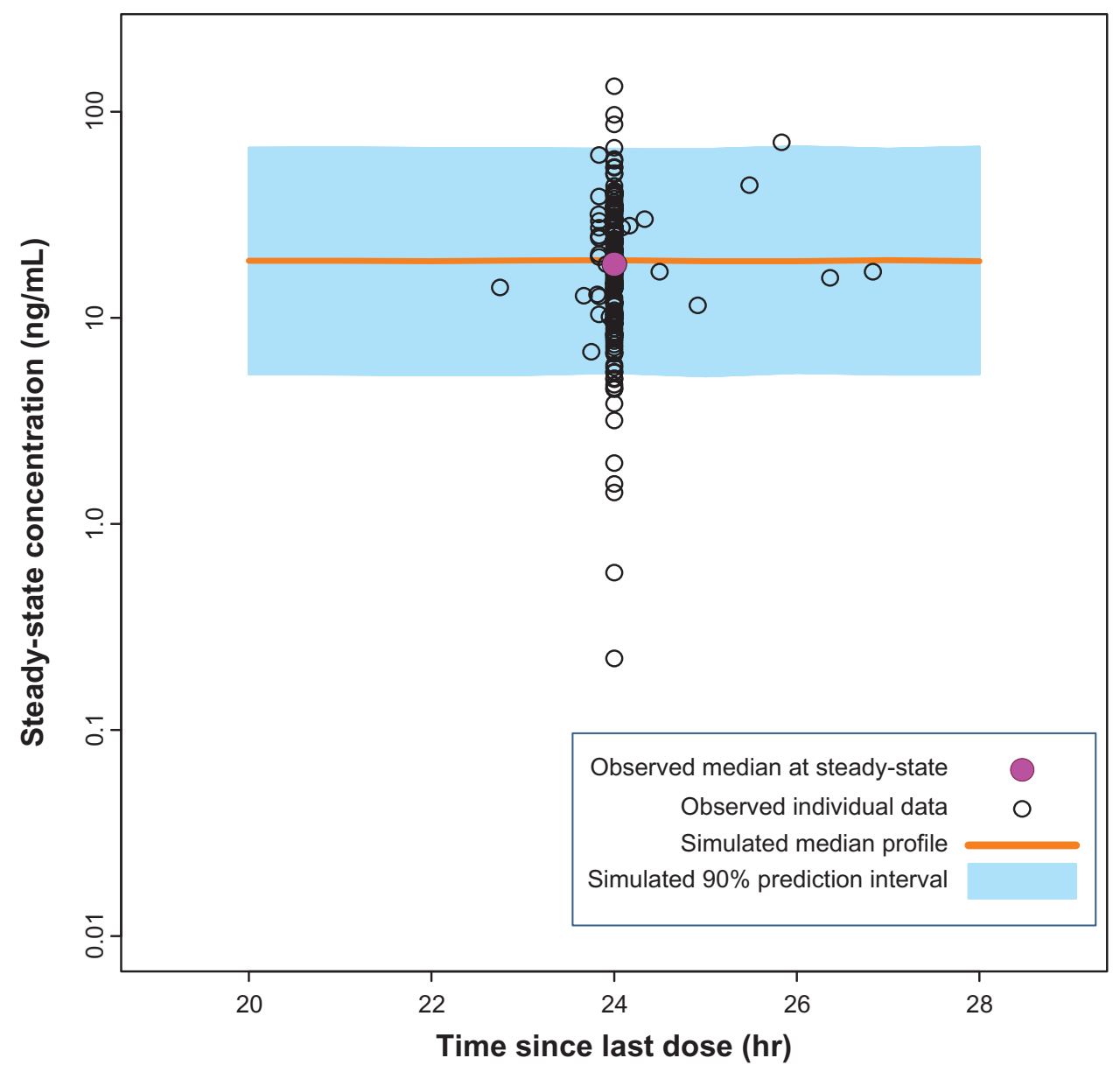

Figure 3 Comparison of model-based projections versus observed steady-state data for the recommended daily dose of paliperidone ER (6 mg). Abbreviation: ER, extended-release.

observed with the recommended initiation regimen (Table 3). No new or clinically significant treatment-emergent adverse events were noted with the highest initiation regimen.

The overall incidence rates and specific reports of treatmentemergent adverse events were generally similar across the two

Table 2 Quantitative comparison of simulated peak exposures with paliperidone palmitate initiation regimens

\begin{tabular}{ll}
\hline Set of simulations & $\begin{array}{l}\text { Median peak concentration } \\
\text { (\% change versus } \\
\text { comparator group) }\end{array}$ \\
\hline First set & \\
PP I50 mg eq/100 mg eq day I/day 8 & $29.8 \mathrm{ng} / \mathrm{mL}(\mathrm{N} / \mathrm{A})$ \\
PP I50 mg eq/100 mg eq day I/day 4 & $31.2 \mathrm{ng} / \mathrm{mL}(4.8 \%)$ \\
PP I50 mg eq/100 mg eq day I/day I2 & $26.7 \mathrm{ng} / \mathrm{mL}(-10 \%)$ \\
Second set & \\
PP I50 mg eq/150 mg eq day I/day $8^{\text {b }}$ & $34.6 \mathrm{ng} / \mathrm{mL}(\mathrm{N} / \mathrm{A})$ \\
PP I50 mg eq/100 mg eq day I/day 4 & $31.2 \mathrm{ng} / \mathrm{mL} \mathrm{(-9.9 \% )}$ \\
PP I50 mg eq/100 mg eq day I/day 8 & $29.8 \mathrm{ng} / \mathrm{mL} \mathrm{(-14 \% )}$ \\
PP I50 mg eq/100 mg eq day I/day I2 & $26.7 \mathrm{ng} / \mathrm{mL} \mathrm{(-23 \% )}$ \\
\hline
\end{tabular}

Notes: a Comparator group, recommended initiation dosage; 'bomparator group, highest clinically tested initiation dosage.

Abbreviations: PP, paliperidone palmitate; $m g$ eq, milligram equivalents; N/A, not applicable. initiation regimens (PP $150 \mathrm{mg}$ eq on both days 1 and 8 versus $150 \mathrm{mg}$ eq on day 1 and $100 \mathrm{mg}$ eq on day 8). Headache, insomnia, akathisia, anxiety, schizophrenia, diarrhea, injection site pain, fatigue, nasopharyngitis, and tachycardia were reported in $\geq 5 \%$ of patients in any treatment group (Table 3 ).

Overall, there were very few serious treatment-emergent adverse events observed in study NCT00590577, ${ }^{8}$ and were limited to psychiatric events that were likely because of inadequate treatment of the underlying disease. No safety signal was detected for the 150/150 mg eq treatment group on the basis of these findings. Likewise, the pattern of serious treatmentemergent adverse events in the study NCT01150448 5 was consistent with worsening of the underlying disease state. ${ }^{5}$ Neither the nature nor the frequency of serious treatment-emergent adverse events in the study NCT01150448 suggested a new safety signal for patients treated with PP $150 \mathrm{mg}$ eq on both day 1 and day 8 .

\section{Discussion}

The previously recommended initiation regimen of PP supported administration of a second initiation dose within 2 days 
A

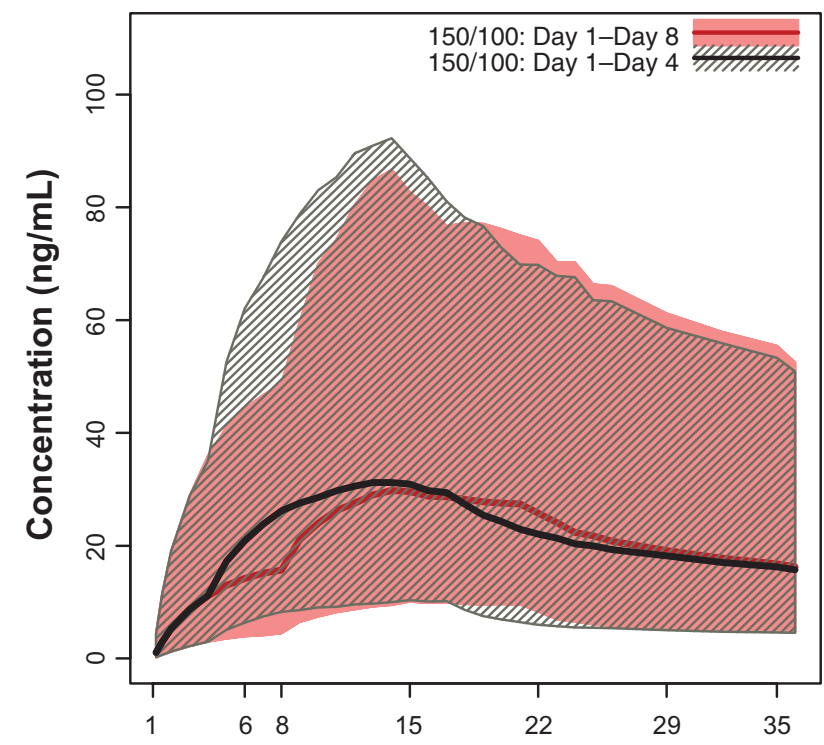

B

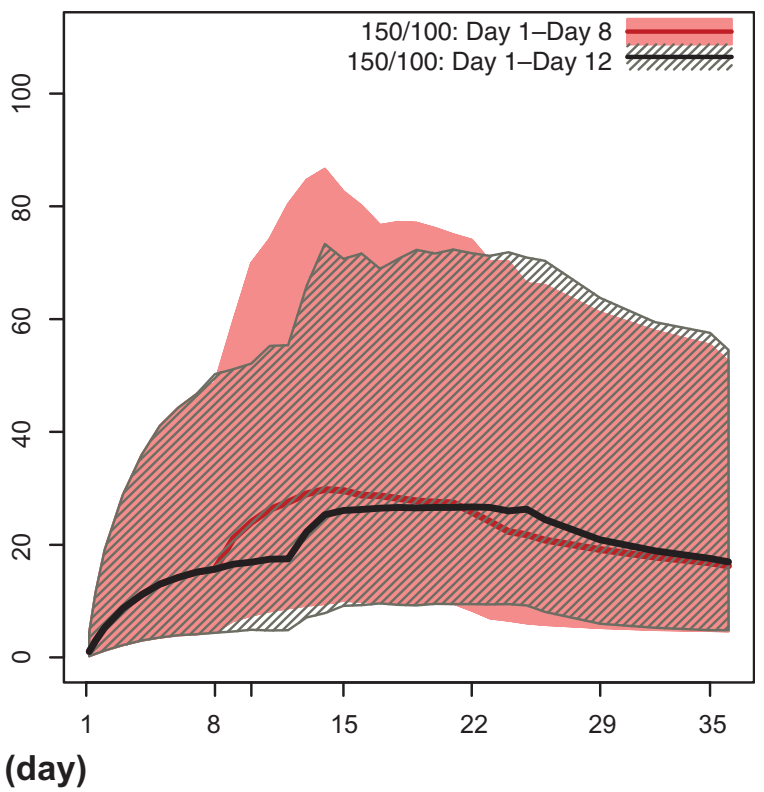

Figure 4 Pharmacokinetic simulations of the PP with second initiation dose (day 8 ) window expanded to \pm 4 days. (A) PP I50 mg eq on day I and I00 mg eq on day 8 versus $150 \mathrm{mg}$ eq on day I and $100 \mathrm{mg}$ eq on day 4 . (B) PP $150 \mathrm{mg}$ eq on day I and $100 \mathrm{mg}$ eq on day 8 versus $150 \mathrm{mg}$ eq on day I and I00 mg eq on day 12.

Notes: $Y$ axis represents paliperidone concentrations in $\mathrm{ng} / \mathrm{mL}$. Lines and shaded areas (pink and gray hatched regions) represent the medians and $90 \%$ prediction intervals. Abbreviations: PP, paliperidone palmitate; $\mathrm{mg}$ eq, milligram equivalents.

of the recommended day 8 injection (days 6 through 10) when the scheduled day 8 dose could not be administered on time. This previously suggested a \pm 2 day window around the recommended day 8 injection did not have a clinically significant impact on plasma paliperidone concentrations. ${ }^{3}$ The modeling results presented here provide support for a more flexible initiation schedule with a \pm 4 day dosing window for administration of the second dose, ie, the second injection can occur between day 4 and day 12 , to avoid a missed day 8 injection and offer a more convenient dosing schedule for stable patients (approved by the FDA in August 2012). ${ }^{4}$ This increased flexibility in initiation is also valuable clinically, because increasing restrictions on length of hospital stay for acute treatment of psychosis make it difficult to complete initiation of PP in many inpatient settings. Furthermore, once discharged from the hospital, follow-up visits may not
A

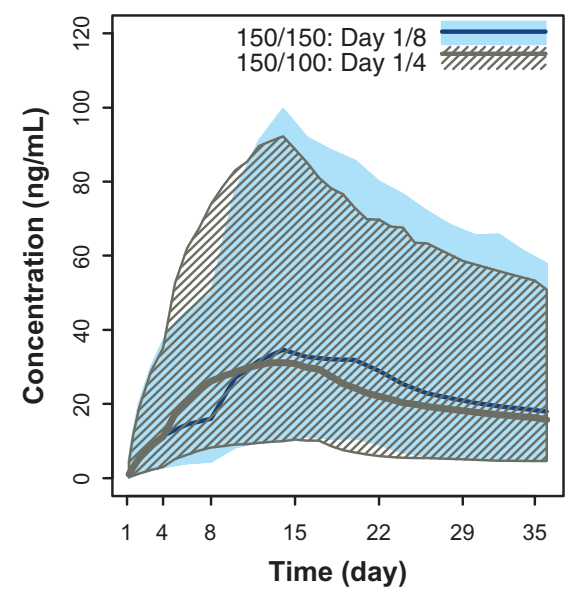

B

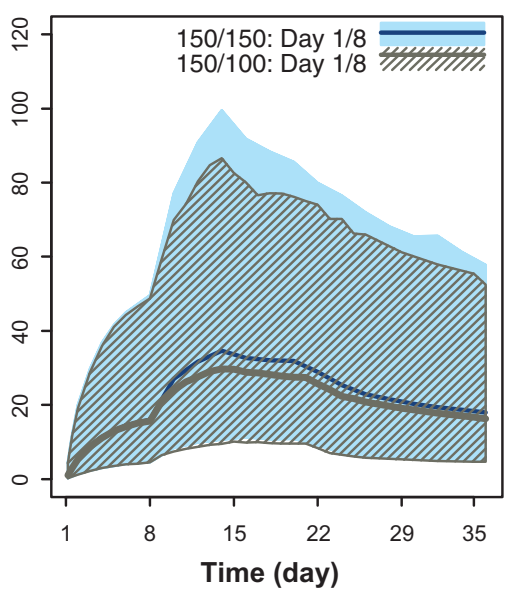

C

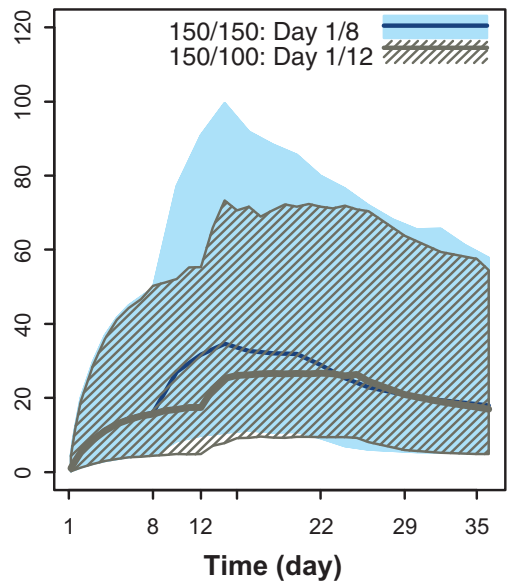

Figure 5 Pharmacokinetic simulations for PP doses $150 \mathrm{mg}$ eq and $100 \mathrm{mg}$ eq with day $\mathrm{I} /$ day 4 , day $\mathrm{I} /$ day 8 , and day $\mathrm{I} /$ day $\mathrm{I} 2$ initiation regimens compared with the highest initiation regimen ( $150 \mathrm{mg}$ eq/day I followed by $150 \mathrm{mg}$ eq/day 8). (A) PP I50 mg eq on both days I and 8 versus I50 mg eq on day I and I00 mg eq on day 4 . (B) PP I50 mg eq on both days I and 8 versus $150 \mathrm{mg}$ eq on day I and $100 \mathrm{mg}$ eq on day 8 . (C) PP I50 mg eq on both days I and 8 versus I50 mg eq on day I and I00 mg eq on day I2.

Notes: $\mathrm{Y}$ axis represents paliperidone concentrations in $\mathrm{ng} / \mathrm{mL}$. Lines and shaded areas (blue and gray hatched regions) represent the medians and $90 \%$ prediction intervals. Abbreviations: PP, paliperidone palmitate; $\mathrm{mg}$ eq, milligram equivalents. 
A

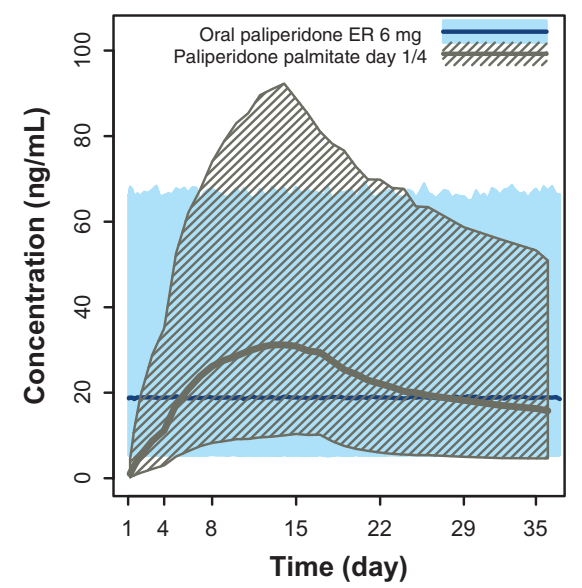

B

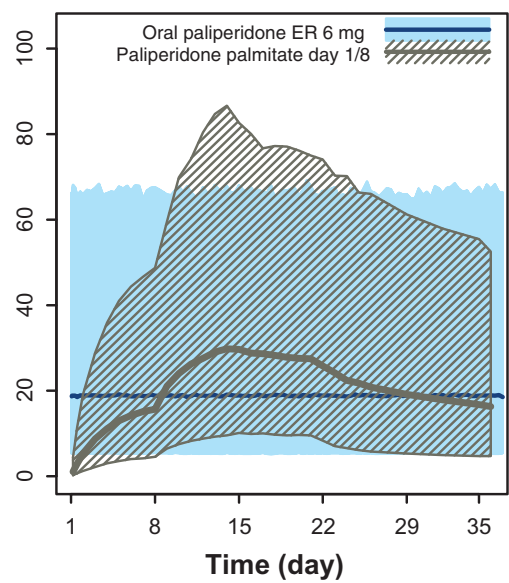

C

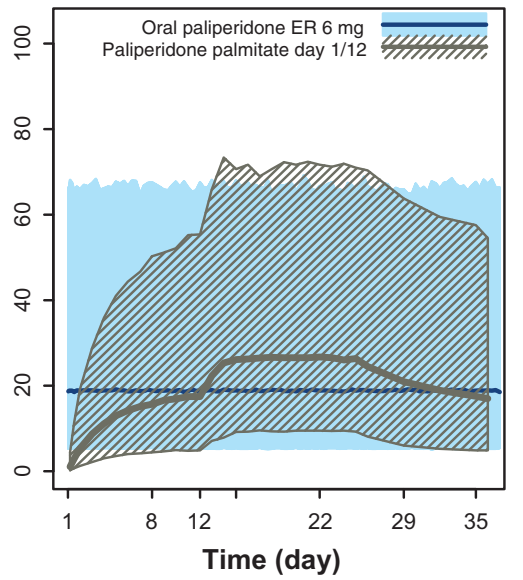

Figure 6 Pharmacokinetic simulations for PP doses $150 \mathrm{mg}$ eq and $100 \mathrm{mg}$ eq with day I/day 4, day I/day 8, and day I/day 12 initiation regimens compared with the recommended daily dose of paliperidone ER $(6 \mathrm{mg}$ ). (A) Steady-state $6 \mathrm{mg}$ paliperidone ER versus PP I50 mg eq on day I and I00 mg eq on day 4 . (B) Steady-state $6 \mathrm{mg}$ paliperidone ER versus PP $150 \mathrm{mg}$ eq on day I and I00 mg eq on day 8 . (C) Steady-state $6 \mathrm{mg}$ paliperidone ER versus PP I50 mg eq on day I and I00 mg eq on day I2. Notes: $Y$ axis represents paliperidone concentrations in $\mathrm{ng} / \mathrm{mL}$. Lines and shaded areas (blue and gray hatched regions) represent the medians and $90 \%$ prediction intervals. Abbreviations: PP, paliperidone palmitate; ER, extended-release; $\mathrm{mg}$ eq, milligram equivalents.

be scheduled until several weeks after the discharge. Such gaps in treatment for patients whose symptoms are not fully stabilized may lead to clinical decompensation and rapid rehospitalization.

It has been shown that gaps in medication of as few as 1-10 days can double the likelihood (odds ratio 1.98) of hospitalization due to relapse ${ }^{13}$ and lead to increased suicide attempt rates. ${ }^{14}$ Relapses are associated with higher costs for inpatient services as well as for outpatient services and medications. ${ }^{15}$ Because of the close links between psychotic relapse and noncompliance with antipsychotic medication,

Table 3 Treatment-emergent adverse events reported in $\geq 5 \%$ of patients in any dose arm, by clinical trial

\begin{tabular}{|c|c|c|c|}
\hline \multirow[t]{2}{*}{ PP dosage } & \multicolumn{2}{|c|}{ NCT00590577 $^{8}$} & \multirow{2}{*}{$\begin{array}{l}\text { NCTO I I } 50448^{5} \\
\text { I } 50 \mathrm{mg} \mathrm{eq} / \\
\text { I } 50 \mathrm{mg} \mathrm{eq} \\
\text { day I/day } 8 \\
(\mathrm{n}=\mathrm{I} 99)\end{array}$} \\
\hline & $\begin{array}{l}150 \mathrm{mg} \mathrm{eq} / \\
100 \mathrm{mg} \mathrm{eq} \\
\text { day I/day } 8 \\
(\mathrm{n}=76)\end{array}$ & $\begin{array}{l}150 \mathrm{mg} \mathrm{eq} / \\
150 \mathrm{mg} \mathrm{eq} \\
\text { day } 1 / \text { day } 8 \\
(\mathrm{n}=76)\end{array}$ & \\
\hline $\begin{array}{l}\text { Patients } \\
\text { with TEAEs, n (\%) }\end{array}$ & $42(55.3)$ & $5 I(67.1)$ & $126(63.3)$ \\
\hline Headache & $6(7.9)$ & $7(9.2)$ & $19(9.5)$ \\
\hline Akathisia & $5(6.6)$ & $4(5.3)$ & $12(6.0)$ \\
\hline Injection site pain & $7(9.2)$ & $7(9.2)$ & $26(13.1)$ \\
\hline Insomnia & $5(6.6)$ & $8(10.5)$ & $17(8.5)$ \\
\hline Anxiety & $4(5.3)$ & $3(3.9)$ & $6(3.0)$ \\
\hline Schizophrenia & I (I.3) & $4(5.3)$ & $4(2.0)$ \\
\hline Nasopharyngitis & I (I.3) & $2(2.6)$ & $16(8.0)$ \\
\hline Diarrhea & $4(5.3)$ & $3(3.9)$ & $5(2.5)$ \\
\hline Fatigue & $4(5.3)$ & 0 & 0 \\
\hline Tachycardia & I (I.3) & $\mathrm{I}(\mathrm{I} .3)$ & $16(8.0)$ \\
\hline
\end{tabular}

Abbreviations: PP, paliperidone palmitate; $\mathrm{mg}$ eq, milligram equivalents; TEAEs, treatment-emergent adverse events. it is important to identify ways to improve adherence. Any method that can potentially reduce the need for follow-up after hospital discharge may ultimately lead to lower relapse rates over time. The greater flexibility for providing an earlier second initiation dose should help bridge these problems in continuity of care for unstable, recently relapsed patients and so support continuous effective antipsychotic exposure to this patient population.

The objectives of this analysis were two-fold. We surmised that injection of the second dose on day 4 is likely to produce a higher $\mathrm{C}_{\max }$. In order to evaluate the potential safety issues, we needed to determine whether this initial higher exposure would still be lower than the exposure observed with the previously tested highest initiation regimen of PP (150 $\mathrm{mg}$ eq on both days 1 and 8). ${ }^{5,8}$ On the other hand, the initiation regimen of $150 \mathrm{mg}$ eq on day 1 with the $100 \mathrm{mg}$ eq injection extended to day 12 may result in a lower paliperidone concentration, which may fall below the therapeutic range, resulting in decreased efficacy. Thus, a simulation exercise was carried out to assess whether expansion of the dose window to avoid a missed dose would likely pose either an efficacy or safety concern.

The highest initiation regimen of PP (150/150 mg eq) previously studied has been found to be generally well tolerated and has a safety profile similar to the currently recommended initiation regimen (150/100 mg eq, Table 3$)$. A comparison of the $150 / 100 \mathrm{mg}$ eq and $150 / 150 \mathrm{mg}$ eq groups indicated that the frequency, but not type, of treatment-emergent adverse events was numerically increased with the dosing regimen of $150 \mathrm{mg}$ eq on both days 1 and day 8 compared with the 
recommended dosing regimen of $150 \mathrm{mg}$ eq on day 1 and $100 \mathrm{mg}$ eq on day 8 . This suggests a dose-dependent relationship for overall frequency of treatment-emergent adverse events and also that advancing the day 8 injection to day 4 may be associated with a small increase in risk for developing treatment-emergent adverse events from previously identified categories in some patients. However, a review of the overall pattern of treatment-emergent adverse events did not identify a new or important increased risk that would be anticipated with the expanded dosing window. Although indirect evidence, the tolerability profile associated with the highest initiation regimen (150/150) supports the safety of the initiation regimen (150/100) with the second dose administered on day 4 . This is because the simulated paliperidone $\mathrm{C}_{\max }$ with an initiation regimen of $150 \mathrm{mg}$ eq on days 1 and 8 was higher than that predicted with an initiation regimen of $150 \mathrm{mg}$ eq on day 1 and $100 \mathrm{mg}$ eq on day 4 .

It should be noted that some patients may be prone to tachycardia, extrapyramidal symptoms, orthostasis, or somnolence and sedation around the time of the highest plasma concentration. In these cases, it is prudent for the physician to be vigilant for occurrence of these symptoms after the second initiation dose on day 4. In addition, the initiation doses should be reduced to $100 \mathrm{mg}$ eq and $75 \mathrm{mg}$ eq (from $150 \mathrm{mg}$ eq and $100 \mathrm{mg}$ eq) in patients with mild renal impairment because systemic exposure is increased in these patients due to reduced drug excretion.

In the open-label study (NCT011504485), nasopharyngitis and tachycardia were reported in $8 \%$ of patients, which was higher than the incidence rate for these same adverse events reported in the other double-blind study (NCT00590577, ${ }^{8}$ see Table 3). To understand these findings, a separate pooled analysis of data from the few previous double-blind, placebo-controlled studies was conducted. The results of this pooled analysis showed that the incidence of nasopharyngitis in the PP-treated patients was $27 / 1293(2 \%)$ and $8 / 510(2 \%)$ in the placebo-treated patients. A similar pooled analysis of data from two double-blind, placebo-controlled studies (NCT00147173, ${ }^{16}$ NCT00101634 $\left.{ }^{17}\right)$ showed that the incidence of tachycardia was 2/611 $(<1 \%)$ in PP-treated patients and 1/262 $(<1 \%)$ in placebo-treated patients. Given the variability associated with spontaneous reporting of adverse events in clinical studies, the incidence rates noted above (8\%) do not appear to be unusual.

Comparison of paliperidone exposure using the recommended daily dose of paliperidone extended-release $6 \mathrm{mg}$ with the initiation regimens of $150 \mathrm{mg}$ eq on day 1 and
$100 \mathrm{mg}$ eq on day 4 , day 8 , or day 12 showed that the plasma concentrations of paliperidone achieved with the three different initiation regimens were similar to those obtained with $6 \mathrm{mg}$ of paliperidone extended-release. Thus, it is unlikely that using an expanded dose window around the day 8 injection (ie, day 4, day 12) would affect the efficacy of PP if the patient's condition is clinically well managed.

Population-based pharmacokinetic models allow characterization of drug absorption and disposition in patients, and this understanding can support the selection or justification of dosing strategies for inclusion in the drug's labeling information. Thus, one of the objectives of the current analysis was to use model-based simulations to avoid additional clinical trials with alternative dosing regimens that would be more convenient, and equally safe and effective. This objective was achieved with the current analysis and the proposed dosing regimen was accepted by the FDA and led to a label update.

The findings of simulation exercises should be interpreted in perspective because they are based on pharmacokinetic bridging and safety considerations. Due to the relatively small sample size, generalizability of the safety findings reported here to a general population receiving paliperidone palmitate remains limited, and currently no clinical studies have been specifically conducted to examine the effect of this expansion. The population pharmacokinetic model used for the simulation exercises assumes complete patient adherence in the simulated virtual patients. However, continuous effective exposure is highly likely to be increased with PP because adherence is required monthly rather than daily with this product. Furthermore, knowledge of adherence is certain with an injectable medication that is provided by a health care professional. Additionally, if any dose is missed out it can be quickly identified and addressed within a window that is much larger than that available for oral medications with a short half-life.

\section{Conclusion}

An expansion of the day 8 dose window for PP to \pm 4 days appears to have minimal effect on plasma paliperidone concentrations, as indicated by model-based simulations, and it will likely have a limited impact on the overall tolerability or efficacy of PP in patients for whom use of the expanded window is necessary to avoid a missed dose. This wider dosing window supports more practical clinical initiation of PP in the hospital setting, particularly in those situations where the duration of hospital stay will be short. 


\section{Disclosure}

This research was funded by Janssen Research and Development, LLC. MNS, IN, and SG are employees of Janssen Research and Development, LLC, USA. BR is an employee of Janssen Research and Development, LLC, a Division of Janssen Pharmaceutica NV, Belgium. JKS and LA are employees of Janssen Scientific Affairs, LLC, USA. All of these companies are Johnson and Johnson companies. Sarika Shirke (SIRO Clinpharm Pvt Ltd) provided writing assistance and Wendy P Battisti (Janssen Research and Development, LLC) provided additional editorial support for this manuscript. This work was presented as a poster at the 24th Annual US Psychiatric and Mental Health Congress, November 7-10, 2011, Las Vegas, NV, USA.

\section{References}

1. Invega ${ }^{\circledR}$ Sustenna ${ }^{\circledR}$ prescribing information, 2012. Available from: http:// www.invegasustenna.com/important-product-information. Accessed November 8, 2012.

2. Gopal S, Gassmann-Mayer C, Palumbo J, Samtani MN, Shiwach R, Alphs L. Practical guidance for dosing and switching paliperidone palmitate treatment in patients with schizophrenia. Curr Med Res Opin. 2010;26:377-387.

3. Samtani MN, Gopal S, Gassmann-Mayer C, Alphs La, Palumbo J. Dosing and switching strategies for paliperidone palmitate based on population pharmacokinetic modelling and clinical trial data. CNS Drugs. 2011;25:829-845.

4. Food and Drug Administration, Department of Health and Human Services; Supplement Approval, 2012. Available from: http://www. accessdata.fda.gov/drugsatfda_docs/appletter/2012/022264Orig1s0051 tr.pdf. Accessed December 10, 2012.

5. Coppola D, Liu Y, Gopal S, et al. A one-year prospective study of the safety, tolerability and pharmacokinetics of the highest available dose of paliperidone palmitate in patients with schizophrenia. BMC Psychiatry. 2012;12:26.

6. Pandina G, Lane R, Gopal S, et al. A double-blind study of paliperidone palmitate and risperidone long-acting injectable in adults with schizophrenia. Prog Neuropsychopharmacol Biol Psychiatry. 2011;35: 218-226.
7. Kramer M, Litman R, Hough D, et al. Paliperidone palmitate, a potential long-acting treatment for patients with schizophrenia. Results of a randomized, double-blind, placebo-controlled efficacy and safety study. Int J Neuropsychopharmacol. 2010;13:635-647.

8. Pandina GJ, Lindenmayer JP, Lull J, et al. A randomized, placebocontrolled study to assess the efficacy and safety of 3 doses of paliperidone palmitate in adults with acutely exacerbated schizophrenia. $J$ Clin Psychopharmacol. 2010;30:235-244.

9. De Meulder M, Remmerie BM, de Vries R, et al. Validated LC-MS/ MS methods for the determination of risperidone and the enantiomers of 9-hydroxyrisperidone in human plasma and urine. J Chromatogr $B$ Analyt Technol Biomed Life Sci. 2008;870:8-16.

10. Samtani MN, Vermeulen A, Stuyckens K. Population pharmacokinetics of intramuscular paliperidone palmitate in patients with schizophrenia: a novel once-monthly, long-acting formulation of an atypical antipsychotic. Clin Pharmacokinet. 2009;48:585-600.

11. Cirincione B, Redman M, Fiedler-Kelley J, Ludwig E, Vermeulen A. Population pharmacokinetics of paliperidone ER in healthy subjects and patients with schizophrenia. Paper presented at the Annual Meeting of the American Society for Clinical Pharmacology and Therapeutics, March 21-24, 2007, Anaheim, CA.

12. Duffull SB, Aarons L. Development of a sequential linked pharmacokinetic and pharmacodynamic simulation model for ivabradine in healthy volunteers. Eur J Pharm Sci. 2000;10:275-284.

13. Weiden PJ, KC, Grogg A, Locklear J. Partial compliance and risk of rehospitalization among California Medicaid patients with schizophrenia. Psychiatr Serv. 2004;55:886-891.

14. Herings RM, Erkens JA. Increased suicide attempt rate among patients interrupting use of atypical antipsychotics. Pharmacoepidemiol Drug Saf. 2003;12:423-424.

15. Ascher-Svanum H, Zhu B, Faries DE, et al. The cost of relapse and the predictors of relapse in the treatment of schizophrenia. BMC Psychiatry. 2010;10:2.

16. Gopal S, Hough D, Xu H, et al. Efficacy and safety of paliperidone palmitate in adult patients with acutely symptomatic schizophrenia: a randomized, double-blind, placebo-controlled, dose-response study. Int Clin Psychopharmacol. 2010;25:247-256.

17. Nasrallah HA, Gopal S, Gassmann-Mayer C, et al. A controlled, evidencebased trial of paliperidone palmitate, a long-acting injectable antipsychotic, in schizophrenia. Neuropsychopharmacology. 2010;35:2072-2082.
Neuropsychiatric Disease and Treatment

\section{Publish your work in this journal}

Neuropsychiatric Disease and Treatment is an international, peerreviewed journal of clinical therapeutics and pharmacology focusing on concise rapid reporting of clinical or pre-clinical studies on a range of neuropsychiatric and neurological disorders. This journal is indexed on PubMed Central, the 'PsycINFO' database and CAS.

\section{Dovepress}

The manuscript management system is completely online and includes a very quick and fair peer-review system, which is all easy to use. Visit http://www.dovepress.com/testimonials.php to read real quotes from published authors. 